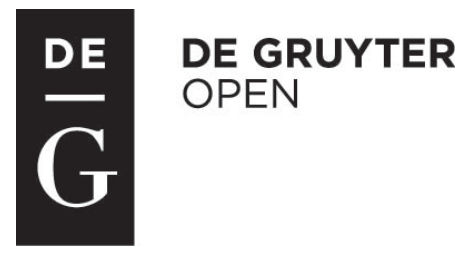

Przedsiębiorczość i Zarządzanie Entrepreneurship and Management University of Social Sciences Publishing House

ISSN 1733-2486

Volume XV, Issue 2, pp. 63-73

DOI 10.2478/eam-2014-0017

Łukasz Sułkowski

University of Social Sciences

Michał Chmielecki

University of Social Sciences

\title{
The use of Social Networking Sites in modern recruitment - empirical study
}

\begin{abstract}
Current changes in technology and the role of the Internet open up new opportunities for companies both to communicate and to work. The fact that Social Media entered the business landscape, and in particular the recruitment landscape leads to a demand for knowledge about recruitment trends regarding social media. Contemporary social media and recruitment texts have been reviewed in order to identify what impact social media is having on the recruitment industry. It focuses on how companies and recruitment professionals are taking advantage of the social media landscape to recruit talented people. Relevant existing research has been reviewed and primary research conducted (both qualitative and quantitative). The authors have conducted 8 IDIs with recruiter from various industries. The latter consisted of 147 CAWIs with employees from various Polish organizations from several different industries. The article presents interesting results that can be especially useful for recruitment managers, specialists and company owners. It is recommended that in order to gain a fuller picture of the issues underlying the findings, quantitative research on a bigger scale should be undertaken.
\end{abstract}

Key-words: social media, social networking sites, recruitment industry, research results.

\section{Introduction}

The current economic crisis offers organizations the possibility to rethink their recruitment activities and employer branding strategies. As fewer vacancies are being created and only a limited number of new employees are hired, the quest 
for the right candidates who can be efficient integrated in the organization is perhaps becoming more significant. Additionally rapid changes in technology open up new opportunities for companies to communicate and work. As a consequence of this constant changes and due to the growing importance of the Internet, social media create various opportunities for recruiters and their communications. This paper looks at the impact social media is having on the recruitment industry. It focuses on how companies and recruitment professionals are taking advantage of the social media landscape to recruit talented people.

The authors have formulated several research questions:

RQ1: Which tools from social media are used most often by recruiters in Polish organizations?

RQ2: Are non-professional SNSs (e.g. Facebook) used as often in the recruitment process as professional SNSs (e.g. Goldenline.pl)

RQ3: Do recruiters think that social media recruitment methods will replace traditional recruitment methods?

\section{Social media and Social Networking Sites}

Social media is a relatively new concept, therefore social media experts have not finished to debate a proper definition of the term, and deciding on a universally accepted definition may prove impossible. Nevertheless, taking into account definitions from several social media experts assists in determining a reasonable definition - one that accurately describes the core purpose of social media.

\section{Figure 1. Social media development from 1995 to 2008}

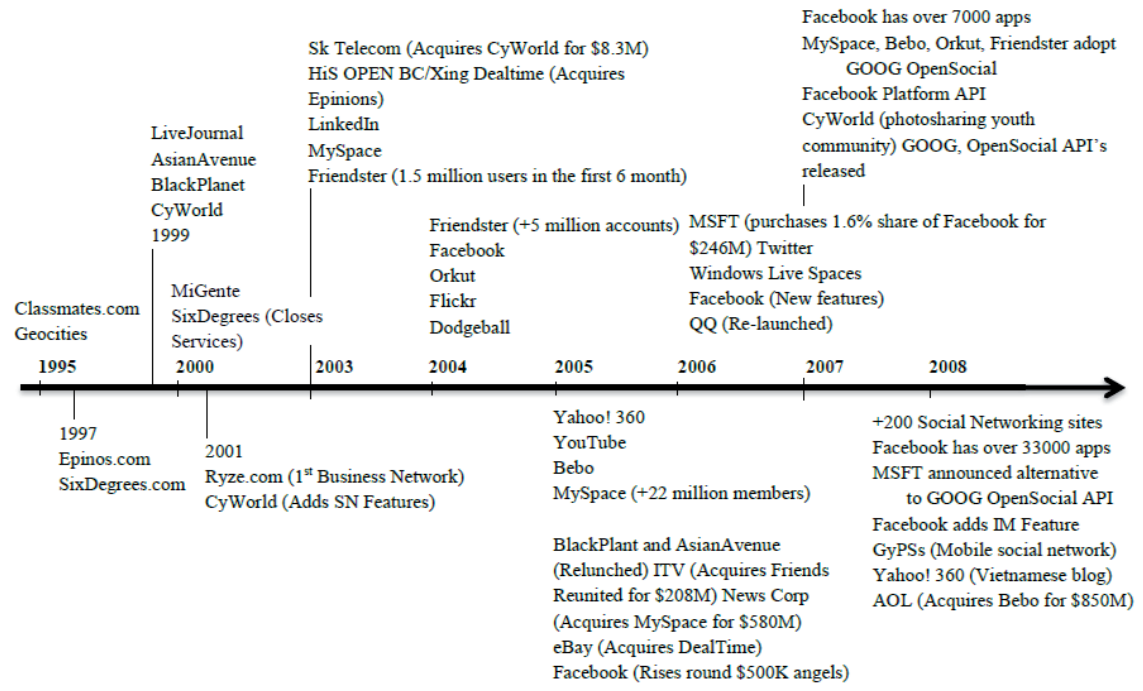

Source: Trebnick 2008. 
Safko and Brake [2009, p.6] observe that social media "refers to activities, practices, and behaviors among communities of people who gather online to share information, knowledge, and opinions using conversational media". Weinberg [2009, p. 1]. notes that social media "relates to the sharing of information, experiences, and perspectives throughout community-oriented websites". Comm [2009] believes that social media is content that has been created by its audience. The Universal McCann report refers to social media as "online applications, platforms and media which aim to facilitate interaction, collaboration, and the sharing of content"[Universal Mccann 2009, p. 10]. The preceding definitions describe various aspects of social media but do not grasp its essence.

Palmer and Koenig-Lewis [2009, p.162] divide social media into following categories:

- blogs,

- social networks,

- content communities,

- forums / bulletin boards,

- content aggregators.

Zarrella offers a basic definition that brings clarity to the term: According to him social media consists of online technologies that facilitate the creation and distribution of content [Zarella 2010]. Concise and simple, this definition lays the foundation for a proper understanding of additional facets of social media.

According to Zarella [2010], social media uses many forms:

- blogs,

- micro blogs,

- social networks,

- media sharing sites,

- social bookmarking and voting sites,

- review sites,

- forums,

- virtual worlds.

SNS - a social networking site is the phrase used to describe any Web site that enables users to create public profiles within that Web site and form relationships with other users of the same Web site who access their profile. SNSs have different rules for establishing connections, but they often allow users to view the connections of a confirmed connection and even suggest further connections based on a person's established network. Some social networking 
websites like LinkedIn are used for establishing professional connections, while sites like Facebook straddle the line between private and professional.

\section{Recruitment, social media and social networking sites}

Human resource management in a professional business context entails the effective and efficient management of an organization's employees toward the achievement of desirable objectives and goals. Human resources management has replaced its predessors such as personnel administration and personnel management by integrating traditional management elements such as:

- human resource development,

- job design,

- recruitment and selection,

- rewards systems, career management, with the strategic objectives of the organisation.

Human resources management perceives employees in a similar way to other resources such as finance or technology and in that sense they must be effectively managed to ensure the best performance for the whole organisation. Human resources management functions to outline the processes for employee acquistion, development and termination [Compton et al. 2009, p. 2].

Organizations are realizing the importance of human resources. Nevertheless its role in a strategic context is still quite limited when compared to other functions. As more firms are embracing human resources functions and aligning them with the central business strategy, human resources managers are starting to adopt more influence and become responsible for strategic business decisions. Management often has an old-fashioned view towards human resources management especially when it concerns the retention of key staff. Functions that are evaluated through cost and profit often fall under this dilemma. It is much easier to calculate the direct costs of human resources management activities than the actual benefit these activities may bring to the organization in the short and long term. However, it is more than likely that investing in human resources can deliver valuable and unique contributions to performance enhancement, cost reduction and finally productivity [Emerald Group Publishing Limited 2009].

Recruitment can be described as the "practices and activities carried out by the organization with the primary purpose of identifying and attracting potential employees" [Parry \& Wilson 2009]. Recruitment aims to attract applicants and fill vacancies to maintain proper staff levels to correspond with an organisation's strategy.

Talented people are a prime source for a company's competitive advantage. The search for the best people is a constant battle between companies and 
they have to develop strategies in order to find the best employees. Due to the competitive nature of the employment market, the potential employer must also sell itself and the vacant position to prospective applicants by presenting its employment advantages. Because of that that, the strategic question of finding, attracting and recruiting the best people has become a relevant issue for companies. Small and large companies, career centers, recruiters and staffing firms develop strategic social recruiting plans to create and maintain relationships with prospective candidates through social media and branding tactics. Recruiters can use tools from four main groups (table 1).

Table 1. Recrutiment tools - social media

\begin{tabular}{|l|l|}
\hline Contact SNS & $\begin{array}{l}\text { - Generalist SNS : Facebook, Twitter } \\
\text { - Professional SNS : Linkedin, Viadeo, Xing }\end{array}$ \\
\hline Content SNS & $\begin{array}{l}\text { - Video, photo and document sharing sites: YouTube, Daily } \\
\text { Motion, FlickR, Slideshare }\end{array}$ \\
\hline Publication tools & $\begin{array}{l}\text { - Applicants blogs: personal or professional. } \\
\text { - Employers blogs: corporate, HR, or specialized in a field. }\end{array}$ \\
\hline Discussion tools & - Forums: generalist or specialized in a specific field. \\
\hline
\end{tabular}

Source: own study.

The variety of Social Networking Sites is growing fast and what is worth mentioning there are clear national differences in their usage. According to Kim et al. (2009) there is a diversity of popular Social Networking Sites by continent, region and country. In Europe, for example, Germans use StudiVz, while Hyves is popular in the Netherlands, Portuguese focus on Hi5 and Poles use GoldenLine. Facebook is used on nearly every continent and is the Social Networking Site with the most registered users with more than 1 billion active users [Facebook 2013]. The number of Social Networking Sites has risen enormously during the last years and still keeps on rising.

Although some of both practitioners and researchers claim that social networking will increasingly replace the traditional CV, both candidates and employees are constantly being advised to be selective in what they put online. Online profiles do not necessarily present an accurate picture of the candidate. Some candidates in the marketplace are concerned about the security issues (identity theft etc.) associated with having personal information online. Others are wary of being victims of discrimination by providing employers with demographic information (such as age, race) that could potentially exclude them from the recruitment process. It happens because employers can essentially filter out candidates based on numerous 'subjective' factors such as e.g. 'university attended'. Assessing someone's potential employability based solely on an online profile leaves many possibilities for unethical practices. 


\section{Research methods and findings}

Critical review of literature and statistics has been undertaken to develop a full understanding and insight into the current trends of online recruitment and the factors surrounding it.

This research was a multistep process which used a combination of research methods (see table 1).

\section{Table 2. Research methods}

\begin{tabular}{|c|c|c|}
\hline Research tool & Type of research & Sample size \\
\hline Desk research & Qualitative & - \\
\hline IDI & Qualitative & 8 \\
\hline CAWI & Quantitative & 147 \\
\hline
\end{tabular}

Source: own study.

Both IDIs and CAWIs were conducted among Human Resources (HR) departments of Polish companies. To determine the perceptions and experiences of the HR departments, the author developed a questionnaire based on the constructs derived both form IDs and from the literature review.

147 respondents participated in CAWI. The majority of respondents come from training and consulting sector (19\%), as well as IT (14\%), finance (12\%) and industry (12\%) (see table 3).

\section{Table 3. Researched companies' sectors}

\begin{tabular}{|l|l|}
\hline Training and consulting & $19 \%$ \\
\hline C2C services & $8 \%$ \\
\hline IT & $14 \%$ \\
\hline Media & $7 \%$ \\
\hline Industry & $12 \%$ \\
\hline Finance & $12 \%$ \\
\hline Insurance & $8 \%$ \\
\hline Science, education, research & $6 \%$ \\
\hline FMCG & $5 \%$ \\
\hline Retail & $9 \%$ \\
\hline
\end{tabular}

Source: own study.

The majority of respondents (37\%) work for companies employing more than 250 employees. The smallest group of respondents came from companies employing form 1 to 10 employees. 
Table 4. The size of the company you work for (employees)

\begin{tabular}{|l|l|}
\hline $1-10$ & $13 \%$ \\
\hline $11-49$ & $14 \%$ \\
\hline $50-99$ & $19 \%$ \\
\hline $100-249$ & $17 \%$ \\
\hline$>250$ & $37 \%$ \\
\hline
\end{tabular}

Source: own study.

The majority of respondents were either HR Specialists (46\%) or HR Managers $(42 \%)$ (see table 5$)$.

Table 5. Respondents positions.

\begin{tabular}{|l|l|}
\hline Assistant & $3 \%$ \\
\hline Specialist & $46 \%$ \\
\hline Manager & $42 \%$ \\
\hline Owner & $9 \%$ \\
\hline
\end{tabular}

Source: own study

In the past, to recruit employees, companies would simply advertise in the local press, post jobs online via the company website or on popular job boards. This 'passive approach', many claim, is on the way out. The global phenomenon of social media is having a significant impact on the world of work and on job markets. Social media is no longer a trend which might be included into a company recruitment strategy. For example in 2009 Monster.com reported a 31\% drop in revenue. Regarding on-line tools, Polish recruitment specialists and managers tend to use mostly job search internet portals and social media sites for professionals (see table 6).

Table 6. Online tools used for recruitment (number of total indications)

\begin{tabular}{|l|l|}
\hline Job search internet portals & 129 \\
\hline Social media (professionals) & 121 \\
\hline Social media (general) & 32 \\
\hline Wirtual job fair & 24 \\
\hline Blogs & 11 \\
\hline Microblogs & 9 \\
\hline Discussion groups & 14 \\
\hline Intranet & 32 \\
\hline
\end{tabular}

Source: own study.

Today hiring managers and recruiters find that they need to be more proactive in their approach. This can be accomplished by engaging with talent across 
various social networking platforms. Essentially, companies and recruiters need to be where their candidates are in order to engage them in the recruitment process. Usually the best candidates, who advertise themselves online using social media sites, tend to want to be found rather than having to actually apply for jobs. Nowadays recruiters have to become experts in using social networking technology to find the right candidates.

Study called Candidates 2.0 conducted by the Employer Branding Institute (ebinstitute.pl) showed that $74 \%$ of students and graduates use the Internet to look for work or practical training. However, research indicates that only $21 \%$ of respondents are looking for work, practice or training on such sites as Facebook or Twitter. The majority uses professional sites such as: GoldenLine or Profeo or LinkedIn.

This research shows that the sites which are mostly used by recruiters are: GoldenLine and Profeo (tab. 7).

Table 7. Social media sites used for recruitment (number of total indications)

\begin{tabular}{|l|l|l|}
\hline GoldenLine.pl & & 114 \\
\hline Profeo.pl & 87 \\
\hline LinkedIn.com & 32 \\
\hline Facebook.com & 23 \\
\hline Twitter.com & 6 \\
\hline NK.pl & 4 \\
\hline Other & 19 \\
\hline
\end{tabular}

Source: own study.

According to the previously mentioned study $51 \%$ of surveyed companies have already decided on the activity on social networking sites, promoting their business, informing about the inner life of the company, posting announcements, or looking for workers. The power of the Internet is also stressed by the fact that $78 \%$ of respondents would not accept a job offer from a company which has a bad reputation in the Internet.

Table 8. Do you think social media recruitment will replace other recruitment methods?

\begin{tabular}{|l|l|}
\hline Yes & $3 \%$ \\
\hline No & $93 \%$ \\
\hline Difficult to say & $4 \%$ \\
\hline
\end{tabular}

Source: own study. 
However, as table 7 illustrates $93 \%$ of the respondents do not believe that recruitment through social media will replace other recruitment methods. D. Lewicka notes that Polish recruitment specialists believe that it is the best to start the job search from the Internet. Internet provides both the employee and the employer almost unlimited access to information about the advertisement [Lewicka 2010]. What is more, social media isn't for everyone. 94\% of the respondents believe there is number of limitations associated with its use for recruitment.

Of course there are some quick gains; nevertheless using this method particularly at the executive level can lead to missing out the relationship building and the selection and assessment of individuals, which, if overlooked, can undermine the recruitment process overall.

Social media imposes few rules for recruitment agencies, which may include:

1. Transparency of activities. Any activity in the field of recruitment in social media should not leave behind any doubts.

2. HR principles in social media are not related only to this area of the business. These "social" approach in the recruitment should result of business thinking version 2.0.

3. HR builds the image of the company. Employer branding in Web 2.0. is inextricably linked with the previous point, which relates to the same philosophy. It is impossible to conduct recruitment via social media if the company does not have a strong social media presence and understanding.

4. Viral sharing. Ads shall be designed in such a way they it is easy to share them with other users via social media like Faceebooka, Google+ or Twitter.

\section{Limitations}

This study covers a broad range of topics including human resource management, recruitment as well as social media. It was therefore necessary to give just a general insight into each of these areas. This article does not cover the whole range of activities performed by the recruitment managers and specialists from human resources departments in organizations nor does it analyze the outsourcing of these activities. Social media was introduced although its broader uses and implications were not further examined.

\section{Summary}

Recruiting the best candidates is critical to any company's success and it's organizational culture [see Sułkowski 2012] today and many exciting tools have been created to help them find and source the key talent.

In the past, there was always a question of the value of social media in recruitment processes, but based on this research, it is clear that recruiter be- 
lieve social recruiting is a very helpful method. Social media allows recruiters to find more job candidates than ever before. As a result, recruiters say that social media recruiting improved both the quantity and quality of candidates. It's also much easier to share jobs through social networks because employees can refer jobs to their own networks. It is worth stressing that recruiters review more and more often candidates' social profiles in non-professional SNSs in the hiring process, the content on these profiles could make or break a candidate's chances.

On the one hand social media made the recruitment process more open and democratic on the other leaves open door for unethical practices. The research shows using this method alone takes the 'personal touch' out of relationship building and candidate identification and that it is unlikely to completely replace the traditional recruitment methods in the near future.

Social media is being taken more and more seriously by the recruiters. Increasing number of employers are taking advantage of this growing trend by adapting and supplementing traditional recruitment processes with social media-based methods, therefore it's important for job candidates to pay more attention to how they use it. As more employers begin to use these outlets, recruiting methods will continue to transform.

\section{Bibliography}

Comm J. (2009), Twitter power: How to dominate your market one tweet at a time, Hoboken, NJ: John Wiley \& Sons.

Compton R.-L., Morrissey W., Nankervis A. (2009), Effective Recruitment and Selection Practices, 5th edition. Australia: CCH Australia Limited.

Emerald Group Publishing Limited (2009), HR's time machine trip to top jobs Evolving role makes department central to success, Strategic Direction, Vol. 25, No. 8, pp. 6-9.

Emploer Branding Institute, www.ebinstitute.pl 23.03.2013.

Lewicka D. (2010), Zarzadzanie kapitatem ludzkimi w polskich przedsiębiorstwach. Metody, narzędzia, mierniki, PWN, Warszawa, p. 101.

Safko L., Brake D K. (2009), The social media bible: Tactics, tools \& strategies for business success, Hoboken, NJ: John Wiley \& Sons., p.6.

Palmer A., Koenig-Lewis N. (2009), An experiential, social network-based approach to direct marketing, 'International Journal Of Direct Marketing', Vol. 3. No. 3, p. 162. Parry E., Wilson H. (2009), Factors influencing the adoption of onlinerecruitment, 'Personnel Review', Vol. 38, No. 6, pp. 655-673.

Sułkowski Ł. (2012), Kulturowe procesy zarzadzania, Diffin, Warszawa. 
Trebnick C. (2008), Social media market dynamics and impact on communications infrastructure, Americas Growth Capital.

Universal McCann (2009), Power to the people: Social media tracker wave 4. Retrieved from http://universalmccann.bitecp.com/wave4/Wave4.pdf p. 10., 11.02.2013.

Weinberg T. (2009), The new community rules: Marketing on the social web. Sebastopol, CA: O’Reilly Media, Inc. p.1.

Zarrella D. (2010), The social media marketing book, Sebastopol, CA: O'Reilly Media, Inc. 